\title{
NIF Diagnostic Damage and Design Issues
}

\author{
N. Landen
}

June 24, 1999

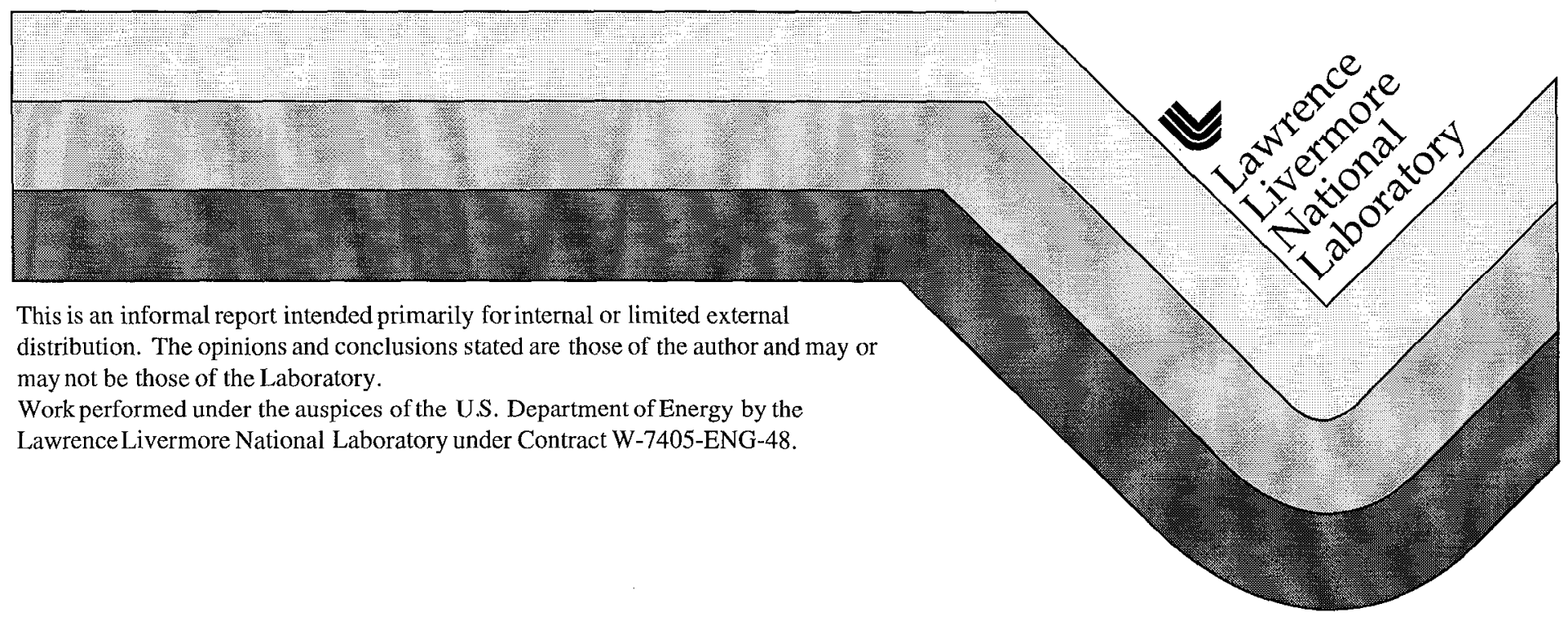




\section{DISCLAIMER}

This document was prepared as an account of work sponsored by an agency of the United States Government. Neither the United States Government nor the University of California nor any of their employees, makes any warranty, express or implied, or assumes any legal liability or responsibility for the accuracy, completeness, or usefulness of any information, apparatus, product, or process disclosed, or represents that its use would not infringe privately owned rights. Reference herein to any specific commercial product, process, or service by trade name, trademark, manufacturer, or otherwise, does not necessarily constitute or imply its endorsement, recommendation, or favoring by the United States Government or the University of California. The views and opinions of authors expressed herein do not necessarily state or reflect those of the United States Government or the University of California, and shall not be used for advertising or product endorsement purposes.

This report has been reproduced directly from the best available copy.

Available to DOE and DOE contractors from the

Office of Scientific and Technical Information

P.O. Box 62, Oak Ridge, TN 37831

Prices available from (423) 576-8401

Available to the public from the

National Technical Information Service

U.S. Department of Commerce

5285 Port Royal Rd.,

Springfield, VA 22161 
June 24, 1999

NIF_0026012

To: Distribution

From: $\quad$ Nino Landen

Subject: $\quad$ NIF Diagnostic Damage and Design Issues

\section{Summary}

The NIF target environment is evaluated with respect to target and diagnostic debris and with respect to instrument survivability in the presence of target debris and radiation. Quantitative estimates are arrived at by extrapolating from Nova and Omega experience using simple scaling arguments. Specifically, we evaluate the closest distance of approach of various components of DIM-based diagnostics such as target mounted pinhole arrays, open detectors, filters, $\mathrm{x}$-ray optics, and spectrometers. We also include constraints on achieving adequate signal-to-noise on $\mathrm{x}$-ray diagnostics. Four of the most important conclusions are as follows:

1) The required full NIF stand-off distance for heavily filtered detectors (e.g. multi-keV $\mathrm{x}$-ray and particle detectors) as determined by concerns of diagnostic debris and diagnostic survivability to debris and radiation is no more than $100 \mathrm{~cm}$.

2) Target mounted pinhole arrays and slits mounted a few $\mathrm{cm}$ from chamber center at NIF will survive long enough to record data and should be an acceptable source of shrapnel debris.

3) DIM-based instrument stand-off distances are compatible with achieving the same photon statistics (or better with ongoing improvements in detector resolution and noise) than available with current Nova and Omega SIM- or TIM-based instrumentation. 
Section II reviews target and diagnostic debris with respect to final optics. Section III reviews debris and radiation with respect to all diagnostic components. The following laser scaling between Nova/Omega and NIF is used throughout unless otherwise specified: laser energy $\mathrm{E}=100 \mathrm{x}$, drive duration $\tau=6 \mathrm{x}$ and hence for a given laser intensity or hohlraum temperature, target size $\mathrm{r}-\sqrt{ }(\mathrm{E} / \tau)=4 \mathrm{x}$. The 100x increase in $\mathrm{E}$ accounts for the fact that many Nova shots were performed with only $20 \mathrm{~kJ}$ and all LLNL Omega shots were performed with only $15 \mathrm{~kJ}$.

\section{Final Optics Damage Issues}

\section{a) Target Debris}

Debris from indirectly driven targets is a primary seed for damage on the Nova and Omega final optics debris shields at 2.4 and $1.5 \mathrm{~m}$ away respectively. Scale 3 ( 8 -mm-long by 4.8 -mm-diameter by $25-\mu \mathrm{m}$-thick) $\mathrm{Au}$ hohlraums routinely shot at Nova with $50-\mu \mathrm{m}$-thick $\mathrm{Cu}$ shields have a mass of $0.1 \mathrm{~g}$. If the figure-of-merit for a debris shield is $\mathrm{x} / \mathrm{cm}^{2}$ of debris, then a NIF debris shield at $7.3 \mathrm{~m} \approx \sqrt{ } 10 \mathrm{x}$ further away could sustain at least a $1 \mathrm{~g}$ target, consistent with estimates stated elsewhere ${ }^{1}$. However, it is likely that the allowable debris fluence on NIF final optics debris shields will be less because of the greater susceptibility to damage given the larger incident $3 \omega$ laser fluences $\left(7 \mathrm{~J} / \mathrm{cm}^{2}\right.$ at NIF vs $1 \mathrm{~J} / \mathrm{cm}^{2}$ at Nova and $1.3 \mathrm{~J} / \mathrm{cm}^{2}$ at Omega).

We now consider the relative importance of debris from target mounted pinhole arrays and slit arrays drilled in high $\mathrm{Z}$ substrates. These pinholes and slits will be used for emission imaging and backlit point or line projection imaging. These substrates will by necessity be within $5 \mathrm{~cm}$ of the target (as set by diffraction limits and laser travel). By simple geometry, the size $c$ of a pinhole substrate used for emission $(M+1)$ or backlight $(M-1)$ imaging is given by:

$$
\mathrm{c}=\mathrm{b} /(\mathrm{M} \pm 1)=\operatorname{nr}(\mathrm{M} /(\mathrm{M} \pm 1)) \approx \mathrm{nr}, \text { for } \mathrm{M} \text { large }
$$

where $\mathrm{b}$ is the detector size, $\mathrm{M}$ is the magnification, $\mathrm{r}$ is the source size and $\mathrm{n}$ is the number of images recorded on a side. Hence, for a $2 \mathrm{~mm}$ 
NIF source size, a typical Ta foil substrate for an $2 \times 2$ pinhole array might be no larger than $5 \times 5 \mathrm{~mm}$ by $50-\mu \mathrm{m}$-thick. Target mounted pinhole arrays (positioned between 4 and $22 \mathrm{~mm}$ from hohlraum center) of these dimensions have been used at Nova ${ }^{2}$ and Omega ${ }^{3}$ with no deleterious effects on debris shields or the detectors they face. These foils have only $20 \mathrm{mg}$ of mass, negligible compared to the NIF ignition hohlraum mass $(\approx 0.2 \mathrm{~g})$. The mass of any required prefilters protecting such pinholes from closure by soft X-ray ablation (see Section IIIb2) will be even smaller as prefilters need only cover the pinhole or slit regions. Moreover, these pinhole arrays will, in the vast majority of cases, be positioned along the chamber equatorial plane or poles where there are not facing indirect-drive beams and debris shields. The same is true incidentally of packages placed on the sides of hohlraums or "halfraums" for basic science and high energy density studies.

\section{b) Diagnostic Debris}

Debris from x-ray ablated NIF diagnostic material should be less of a concern by the following argument scaled from Nova and Omega experience. The diagnostic debris fluence $F_{d}$ reaching final optics at a distance $\mathrm{R}$ due to ablation of diagnostics of cross-sectional area $b^{2}$ and average distance $\mathrm{q}$ from a target driven by a laser energy $\mathrm{E}$ should scale roughly as:

$$
\mathrm{F}_{\mathrm{d}} \sim \mathrm{Eb}^{2} / \mathrm{q}^{2} \mathrm{R}^{2}
$$

Eq. (2) suggests the strategy for limiting diagnostic debris without decreasing signal fluence levels $\sim \mathrm{E} / \mathrm{q}^{2}$ is to limit the increase in detector size $b$ when transitioning from Nova to NIF. Since $b=n r M$ from Eq. (1), and $r$ increases by $4 \mathrm{x}$ on NIF, this strategy amounts to evaluating whether $\mathrm{M}$ and $\mathrm{n}$ can be reduced from current values.

For a given desired spatial resolution at the object plane, the value of $\mathrm{M}$ can only be decreased by a concomitant decrease in the usable resolution element size of the detector. Progress has been made recently in that area. First, we have switched from film (limited by signal-to-noise concerns to 22 by $22 \mu \mathrm{m}$ digitization or coarser) to low noise $4 \mathrm{k}$ by $4 \mathrm{k} 9 \mu \mathrm{m}$ pixel CCD 
arrays ${ }^{4}$. Second, we have demonstrated the presence of fixed pattern noise on gated detectors such as MCPs which has limited the effective resolution and is removable by detailed flatfielding ${ }^{5}$. Third, there are now MCPs with $2 \mathrm{x}$ better intrinsic resolution ${ }^{6}$. So a $2 \mathrm{x}$ reduction in $\mathrm{M}$ should be feasible at NIF.

The value of $n$ (typically 4) can be decreased by noting that many current imaging experiments using static detectors (e.g. X-ray film) average multiple images ${ }^{7}$ to improve signal-to-noise which will not be necessary with x-ray CCDs. For MCP-based gated detectors, typically 4 redundant images are recorded over the same time window (150 ps), which again suggests with better signal-to-noise that a $4 \times 4$ pinhole array can be shrunk to a $4 \times 1$ array. So a $4 x$ reduction in $n^{2}$ and hence a $2 x$ reduction in $n$ should be feasible at NIF.

The combination of a $2 x$ reduction in both $M$ and $n$ compensates for a $4 \mathrm{x}$ increase in $\mathrm{r}$, suggesting we can keep the detector area fixed. Moreover, we will argue in the next section on diagnostic survivability that while $p$ should be increased by $10 \mathrm{x}$ for target-mounted pinholes (from say $4 \mathrm{~mm}$ to 4 $\mathrm{cm}), \mathrm{q}=\mathrm{p}(\mathrm{M} \pm 1)$ need only increase by a smaller amount. This is completely consistent with $\mathrm{M}$ decreasing by $2 \mathrm{x}$.

Since $E$ and $R$ are $100 x$ and $\sqrt{10 x}$ greater on NIF, and the diagnostic area $b^{2}$ can be maintained fixed, $q$ would only need to increase by $\sqrt{ } 10$ by Eq. (2) to maintain the same diagnostic debris fluence at final optics as is present at Nova or Omega. Current SIM-based Nova and Omega diagnostics routinely fielded with detectors at 10 to $38 \mathrm{~cm}$ from chamber center produce no excessive debris shield problems ${ }^{8}$. Hence, by Eq. (2), the same number of NIF detectors at $30 \mathrm{~cm}$ to $1.2 \mathrm{~m}$ distance would be permissible if the same debris level were acceptable at NIF. We note that this $\sqrt{10}$ increase in $\mathrm{q}$ as set by a final optics damage concern is a less stringent condition than that set by some diagnostic damage concerns discussed in the next section.

If the diagnostic debris fluence on NIF debris shields must be kept lower than at Nova, then several options are available. First, one could set 
the minimum primary detector stand-off distance at $1 \mathrm{~m}$ rather than $30 \mathrm{~cm}$ and the average stand-off distance for secondary DIM-based diagnostics at 2 $-3 \mathrm{~m}$. This would decrease the diagnostic solid angle and hence diagnostic debris levels by $5-10 x$. Second, one could use ice coatings ${ }^{9}$ on otherwise exposed instrumentation.

Diagnostic debris from unconverted light impinging on diagnostics can be mitigated by using target mounted pinhole or slit arrays, eliminating the need for traditional long snouts on imagers. Furthermore, as discussed below, unconverted light can be diffracted so as to avoid direct hits on DIMbased diagnostics.

\section{Diagnostic Damage Issues}

We now consider the minimum distance of approach for pinholes, filters, crystals, multilayers and detectors for avoiding damage by target debris and $x$-rays. We ignore damage by neutrons by postulating that those shots attempting and achieving high $\left(>10^{14}\right)$ fusion yield will initially not require close-in $\mathrm{x}$-ray detectors and will produce enough particles to allow for distant particle detectors. We ignore damage by unconverted light. The assumption is that the color separation gratings (CSGs) will be oriented so as to remove unconverted light levels to below $1 \mathrm{~J} / \mathrm{cm}^{2}$ where pinhole arrays and primary detectors are positioned. Current proposed CSG orientations ${ }^{10}$ already preferentially accommodate target mounted pinhole arrays placed on the equatorial plane or along the vertical. We also ignore the case of a high gain (>3) implosion target; if it works, then we will be only too happy to replace any damaged DIM-based diagnostics; if it fizzles, then we may learn why from DIM-based diagnostic data that has survived.

\section{a) Target Debris}

We consider target debris first, separating it into vapor and shrapnel. Vapor is defined as ionized material created by strong shocks and laser and $\mathrm{x}$-ray ablation. Shrapnel is defined as non-vaporized remnants from such sources as stalks, shields and target-mounted pinhole arrays. 


\section{1) Vapor}

The kinetic fluence $F_{v}$ of vapor created from either shocked or ablated material is given by the following:

Shocked: $\quad F_{v}=(3 / 4) m_{v} u_{p}^{2}$

Ablated: $\quad \mathrm{F}_{\mathrm{v}}=(1 / 2)(\mathrm{dm} / \mathrm{dt}) \tau \mathrm{v}_{\mathrm{ex}}{ }^{2}$

where $m_{v}$ is the vapor areal mass density, $u_{p}$ is the shocked particle speed, $\mathrm{dm} / \mathrm{dt}$ is the areal mass ablation rate, $\tau$ is the ablation duration and $v_{\mathrm{ex}}$ is the ablated material exhaust velocity. For indirect-drive, the shocked (ablated) vapor is released outside (inside) of the hohlraum, but will eventually expand. In both cases, $F_{v}$ is roughly proportional to the incident laser or $\mathrm{X}$ ray fluence ${ }^{11}$. For the large class of experiments which use hohlraum drive characterized by a radiation temperature $\mathrm{T}$, the fraction of incident laser energy which ends up as vapor kinetic energy is proportional to $(1-\alpha)$, where $\alpha$ is the hohlraum wall albedo. The rest of the energy is in $x$-ray radiation (principally soft $x$-rays) which is dealt with in Section IIIb. Since $(1-\alpha)$ $\sim 1 / T^{0.7} \tau^{0.4}$, the fraction in vapor energy will if anything decrease with increasing facility size due to increasing hohlraum drive temperature and/or duration ${ }^{11}$. For simplicity, let us assume conservatively that the vapor energy $E_{v}$ scales with incident laser energy $E$. Also assuming for the moment that the vapor expands uniformly in all directions, then postulating a maximum acceptable vapor fluence $F_{v}$ at a detector sets the scaling for minimum detector distance $q \sim \sqrt{E}\left(\right.$ since $F_{v} \sim E_{v} / q^{2} \sim E / q^{2}$ ). Without attempting to calculate $F_{v}$ a priori, we can set a minimum value for the proportionality constant between $q$ and $\sqrt{E}$ by reviewing Nova and Omega experience. For cxamplc, a MCP-based gated detector filtered and protected with $0.5 \mathrm{~mm}$ of $\mathrm{Be}$ and placed at $10 \mathrm{~cm}$ normal to the axis of a hohlraum driven by a $12 \mathrm{~kJ}$ Omega laser pulse recently survived a 12 shot sequence. Hence, we can predict that under the assumption of evenly distributed vapor that such a filtered detector would not be damaged by vapor at $1 \mathrm{~m}$ from a hohlraum driven by a 1.2 MJ NIF shot. 
In the case of a vaporized cylindrical hohlraum endcap, the resultant expansion may be highly directional ${ }^{12}$. Hence, instrument survivability at the hohlraum poles is probably a greater concern than at the midplane. The same concern should also hold for planar packages viewed face-on which are situated either on flat sections of a hohlraum wall or on the ends of "halfraums". In the case of a backlighting measurement, one can at least reduce the odds of diagnostic damage by choosing from which side one views the package.

\section{2) Shrapnel}

Let us now consider the scaling of shrapnel fluence. The assumption here is that the shrapnel fluence is determined by either x-ray ablative acceleration or by energy transfer when hit by vaporized material. If the hit is inelastic and the vapor material is lighter, then the following analysis based on ablative acceleration holds for such a collision as well. In the limit that the ablated areal mass density of potential shrapnel is much smaller than the accelerated shrapnel areal mass density $\mathrm{m}$, the shrapnel velocity $\mathrm{v}$ after a time $\tau$ as given by the rocket equation is:

$$
\mathrm{v}=\left[(\mathrm{dm} / \mathrm{dt}) \tau \mathrm{v}_{\mathrm{ex}}\right] / \mathrm{m}
$$

Hence, the shrapnel source fluence $\mathrm{E}_{\mathrm{s}}$ is:

$$
\mathrm{F}_{\mathrm{s}}=(1 / 2) \mathrm{mv}^{2}=(1 / 2)\left[(\mathrm{dm} / \mathrm{dt}) \tau \mathrm{v}_{\mathrm{ex}}\right]^{2} / \mathrm{m}
$$

Substituting Eq. (4) into (5):

$$
\mathrm{F}_{\mathrm{s}}=2 \mathrm{~F}_{\mathrm{v}}^{2} / \mathrm{mv}_{\mathrm{ex}}^{2}
$$

Consider potential pieces of shrapnel such as target mounted pinholes at distance $\mathrm{p}$ and of total cross-sectional area $\mathrm{A}$ as viewed from the target. If we postulate that the fraction of $\mathrm{x}$-rays escaping the hohlraum (and thereby reaching potential shrapnel) is constant as we transition from Nova-scale to NIF-scale, then the ablated vapor fluence $F_{v}$ at potential shrapnel such as a pinhole substrate is simply proportional to $\mathrm{E} / \mathrm{p}^{2}$. For a given hohlraum 
temperature, maintaining the escaping $x$-ray fraction constant requircs reaching a fixed outside wall surface temperature. From a simple heat capacity argument, this is equivalent to fixing the ratio between the radiation penetration depth $\mathrm{z}$ by the end of the laser drive duration $\tau$ and the initial hohlraum wall thickness $\Delta$. For a diffusive radiation wave ${ }^{11}, z \sim \sqrt{ } \tau$. Since $\tau$ is $6 x$ larger at NIF, maintaining $z / \Delta$ fixed at fixed hohlraum temperature requires a $2.5 \mathrm{x}$ thicker wall. For Nova/Omega hohlraums, the radiation penetration depth is $\sim 3 \mu \mathrm{m}$ in solid density gold ${ }^{11}$ for a temperature of 250 $\mathrm{eV}$. For NIF, the penetration depth at the same temperature is hence $\sim 8 \mu \mathrm{m}$. $3 \mathrm{mg}$ thin-walled Nova and Omega hohlraums constructed from 2-3 $\mu \mathrm{m}$ gold walls backed for support by $100 \mu \mathrm{m}$ of epoxy have been routinely used above $200 \mathrm{eV}$ with no adverse effects. Scaled to NIF, a similar temperature hohlraum would only weigh $\approx 0.1 \mathrm{~g}$ ( $4 \mathrm{x}$ the diameter and $2.5 \mathrm{x}$ the thickness), well below the allowed weight.

Substituting for $F_{v}$, the total shrapnel energy is then:

$$
\mathrm{E}_{\mathrm{s}} \sim 2 \mathrm{~A}\left(\mathrm{E} / \mathrm{p}^{2}\right)^{2} / \mathrm{mv}_{\mathrm{ex}}{ }^{2}
$$

Eq. (7) suggests thicker shrapnel (i.e. m larger) will have less fluence or energy imparted as expected of the momentun conserving, inelastic energy transfer mechanisms described above. Hence, there is probably a worst-case areal density for maximizing potential shrapnel energy; thicker pieces will have less energy and thinner pieces will not become shrapnel (will vaporize instead). However, increasing potential shrapnel mass will eventually lead to pile-up of "rubble" on final optics surfaces, also undesirable. Let us assume for the moment that we can keep the potential shrapnel area A and mass fixed between Nova/Omega and NIF-scale. This appears at least true for target mounted pinholes as discussed above. The radiation driven shrapnel exhaust velocity $\mathrm{v}_{\mathrm{ex}}$ scales as $\sqrt{\mathrm{T}}$ and hence as $\left(E / \tau p^{2}\right)^{1 / 8}$. Under those conditions and substituting for $v_{e x}$ in Eq. (7), the sphere-averaged shrapnel fluence $\mathrm{F}$ at a detector distance $\mathrm{q}$ away from the source of shrapnel is:

$$
\mathrm{F} \sim\left(\mathrm{E} / \mathrm{p}^{2}\right)^{7 / 4} \tau^{1 / 4} / \mathrm{q}^{2} \sim\left(\mathrm{E} / \mathrm{p}^{2}\right)^{7 / 4} / \mathrm{q}^{2}, \text { ignoring weak } \tau \text { dependence }
$$


In reality, there will be a range of shrapnel sizes and associated local shrapnel fluences. We assume for the moment that the distribution of shrapnel is self-similar in all directions (i.e. the same shrapnel size probability distribution applies in all directions). Furthermore, we assume the probability of a detector getting hit by shrapnel follows Poisson statistics (i.e. no hit on most shots). If we make the further assumption that the number of pieces of shrapnel will stay fixed, the probability of a given area detector being hit by shrapnel is just proportional to $1 / \mathrm{q}^{2}$, irrespective of the laser energy. Eq. (8) can then be interpreted as proportional to the average shrapnel energy multiplied by the probability of a detector getting hit by shrapnel, i.e. the probability of detector damage is a function of Eq. (8).

For example, the $\mathrm{MCP}$ detector at $\mathrm{q}=10 \mathrm{~cm}$ at Omega survived because the probability of getting hit by a piece of shrapnel with a fluence and size sufficient to destroy the detector multiplied by the number of shots was $<<1$. If there was on average only one piece of shrapnel of a "destroyer-class" local fluence emitted in a random direction from shot-toshot, the probability of it hitting and thereby destroying the $3.5 \times 3.5 \mathrm{~cm} \mathrm{MCP}$ active area at $10 \mathrm{~cm}$ was $\approx(3.5 / 10)^{2} / 4 \pi \approx 1 \%$. In fact, one shot led to a cracked filter, corresponding to some higher probability, sub-destroyer-class (and hence acceptable) local shrapnel fluence.

Consider the conservative approach to scaling debris to NIF. Keeping the vapor fluence fixed increases $q$ by $\sqrt{ }\left(\mathrm{E}_{\mathrm{NIF}} / \mathrm{E}_{\mathrm{Nova}}\right) \approx 10 \mathrm{x}(1 \mathrm{~m}$ vs $10 \mathrm{~cm})$. By Eq. (7), if we also keep the shrapnel energy fixed by keeping the ratio $\mathrm{E} / \mathrm{p}$ fixed, by increasing $\mathrm{p}$ by $10 \mathrm{x}$ (e.g. from $4 \mathrm{~mm}$ to $4 \mathrm{~cm}$ ), then the probability of a detector being destroyed by shrapnel is $100 \mathrm{x}$ less at NIF than at Nova or Omega! This surprising result arises because the solid angle subtended by a fixed detector area is $100 \mathrm{x}$ less when placed $10 \mathrm{x}$ further away. The downside of placing target mounted pinholes at $\mathrm{p}=4 \mathrm{~cm}$ rather than $4 \mathrm{~mm}$ is $\sqrt{10 x}$ worse diffraction-limited spatial resolution and $10 \mathrm{x}$ less photons collected per resolution element. Some of the spatial resolution may be recovered by noting that much NIF x-ray imaging and backlighting will be performed at shorter wavelengths because of hotter or larger samples. 
Clearly, one would like to increase $\mathrm{p}$ by less than $10 \mathrm{x}$ for NIF target mounted pinholes to maintain current $5 \mu \mathrm{m}$ spatial resolution. The extent to which $\mathrm{p}$ can be kept small will be determined by the form of the distribution of shrapnel energy. Reducing $\mathrm{p}$ would increase the average shrapnel energy per Eq. (8), almost certainly increasing the number of shrapnel pieces of "destroyer-class", hence increasing the probability of detector destruction. The good news is that starting from the conservative strategy of increasing $p$ and $\mathrm{q}$ by $10 \mathrm{x}$ each, we can increase the odds of destruction by $100 \mathrm{x}$ before we reach the current risk levels we operate at on Nova and Omega.

We now consider acceptable values for $\mathrm{p}$ and $\mathrm{q}$ assuming various scenarios for shrapnel energy distribution. The assumption is that the current probability of detector destruction on Nova or Omega is acceptable for NIF. Due to the limited number of shots, the destruction probability can only be estimated as $10 \%$ or less; we assume the real destruction probability is $1 \%$ or less, probably acceptable odds at NIF.

Case a) The shrapnel energy distribution is strongly peaked about some average value, and that average energy is already sufficient to destroy detectors at Nova/Omega. In this case, there is no added risk to the detectors in increasing the shrapnel energy at NIF by keeping p constant since the fraction of "destroyer-class" shrapnel is already close to $100 \%$. The probability for destruction is then simply related to the small probability of a hit, $\sim 1 / \mathrm{q}^{2}$, so whatever value of $\mathrm{q}$ is acceptable at Omega is acceptable at NIF.

Case b) There is no shrapnel energy capable of destroying detectors at Nova/Omega. In this case, one should keep the ratio $\mathrm{E} / \mathrm{p}^{2}$ fixed, ensuring there is also no shrapnel energy capable of destroying detectors at NIF. A worthwhile exercise would be to find the smallest value for $\mathrm{p}$ at Omega that does not lead to likely destruction, and scale by that value. The value for $q$ is now only determined by a vapor damage threshold, which may allow for values of $\mathrm{q}<1 \mathrm{~m}$. The strategy of keeping $\mathrm{E} / \mathrm{p}^{2}$ fixed may not be possible in all cases where shrapnel sources such as shields must be close to fixed size hohlraums. Hence, it is important to minimize mass close to the hohlraum so that it may turn into vapor rather than into shrapnel. 
Case c) The shrapnel energy distribution is broad, but only a small fraction y at the top end of the shrapnel energy distribution is of "destroyerclass". The strategy here follows the strategy presented in Case a) or b), depending on the value of $y$, as outlined below.

The probability $\mathrm{P}_{\Omega}$ of a detector at distance $\mathrm{q}$ being destroyed on any given shot at Omega is:

$$
P_{\Omega}=y x / q^{2}
$$

where $x / q^{2}$ is the normalized probability of a shrapnel hit, and $x$ is proportional to the number of pieces of shrapnel, assumed fixed between Omega and NIF.

Stipulating that the detector destruction probability at NIF, $\mathrm{P}_{\mathrm{NIF}}$, must bc equivalent or less than $P_{\Omega}$ and assuming a NIF detector distance $=10 q$, and a worst case destroyer fraction $\mathrm{y}_{\mathrm{NIF}}=1$ :

$$
\mathrm{P}_{\mathrm{NIF}}=\mathrm{y}_{\mathrm{NIF}} \mathrm{x} /(10 \mathrm{q})^{2}=\mathrm{x} / 100 \mathrm{q}^{2}<\mathrm{yx} / \mathrm{q}^{2}
$$

Hence: $y>.01$

Eq. (11) states that if the fraction of destroyer-class shrapnel is already larger than $1 \%$ at Omega, then the probability of detector destruction at NIF is smaller because the $100 \mathrm{x}$ decrease in NIF detector solid angle more than compensates for $\mathrm{a}<100 \mathrm{x}$ possible increase in destroyer-class shrapnel pieces. If $y>.01$, then there is no restriction on the value of $\mathrm{p}$ as in Case a). If $y<.01$, then the strategy of Case $b$ ) (fixed $E / p^{2}$ ) is required. Given the distribution function for shrapnel energy, we could be more specific on how damage probabilities scale from Nova/Omega to NIF and hence how to scale the value of $p$.

Apart from these statistical arguments, there are target specific strategies that should be investigated for reducing the probability of detector destruction by shrapnel. For example, pinhole substrates can be wedged to 
send the resultant shrapnel in a predetermined direction away from the detector. The x-ray flux reaching a particular source of shrapnel can be mitigated by adding extra filtering near the x-ray source, so that the filter which eventually turns into less harmful vapor soaks up more of the $\mathrm{x}$-ray energy.

\section{b) X-ray Ablation}

We now consider the minimum distance of approach for filters, pinholes, imaging optics and spectrometers for avoiding significant damage from x-rays. We will assume that we match the number of collected photons / resolution element that is acceptable at Nova or Omega scale when transitioning to NIF scale. We evaluate stand-off distances for hard (multi$\mathrm{keV}$ ) and soft $\mathrm{x}$-ray imaging separately. SIM- and TIM-based Nova and Omega diagnostics were originally designed with essentially the same detector stand-off distance for soft and hard $x$-ray applications $(q=50$ and $38 \mathrm{~cm}$, respectively). However, within the limits imposed by shrapnel concerns, it is clear that hard x-ray detectors which sense only a small ( $<$ $1 \%$ ) converted fraction of the total incident laser energy from most targets (NWET volume emitters an exception) can be positioned much closer than soft $\mathrm{x}$-ray detectors, by factors of $\approx 10 \mathrm{x}$, as argued below.

\section{1) Filters}

Here we are concerned only with filters that must remain intact during the shot (e.g. those that provide debris or light shielding of expensive detectors, optics and spectrometers). Pre-filters on hohlraums and on targetmounted pinholes are expendable (just as target-mounted pinholes are) and hence not considered. The fluence on a shielding filter $F_{F}$ at distance $p$ is given by:

$$
\mathrm{F}_{\mathrm{F}} \sim \mathrm{F}_{\mathrm{T}}\left(\mathrm{r}^{2} / \mathrm{p}^{2}\right)
$$

where $\mathrm{F}_{\mathrm{T}}$ is the isotropic target $\mathrm{X}$-ray source fluence and $\mathrm{r}$ the emitting target radius. Assuming the target radiant energy $\left(\sim \mathrm{F}_{\mathrm{T}}{ }^{2}\right)$ scales with the laser energy $\mathrm{E}$ : 


$$
\mathrm{F}_{\mathrm{F}} \sim \mathrm{E} / \mathrm{p}^{2}
$$

Since heavy filters (e.g. $0.5 \mathrm{~mm} \mathrm{Be}$ ) placed $1 \mathrm{~cm}$ from Nova hohlraum midplanes have survived both debris and x-ray damage, Eq. (13) suggests such a filter would survive NIF x-ray fluences at $10 \mathrm{~cm}$. This filter stand-off is acceptable since the minimum NIF detector stand-off has already been determined to be $>10 \mathrm{~cm}$.

For soft x-ray imagers or power sensors where filters are only placed close to the detector plane, scaling from the current $50 \mathrm{~cm}$ soft $\mathrm{x}$-ray detector stand-off distances leads to a $5 \mathrm{~m}$ stand-off at NIF. The larger detector stand-offs for soft X-ray imaging will probably be acceptable because:

1) The broadband soft $x$-ray fluence from backlighters or hohlraums is generally much greater than the hard $x$-ray flucnce (one reason for the large stand-off of soft $x$-ray filters).

2) The detectors are usually more sensitive at longer $\lambda$.

3) The photon statistics are improved by $\sqrt{ } \lambda$ for a given fluence.

4) The photon collection efficiency / resolution element by Eq. (16) is $\sim \mathrm{a}^{4}$, hence $\sim \lambda^{2}$ for diffraction-limited resolution (where a is set $\sim$ $\sqrt{ }(\mathrm{p} \lambda))$.

\section{2) Pinholes}

Consider pinholes at a distance $\mathrm{p}$ exposed to either backlighter target emission or target self-emission characterized by a radius $r$, a fluence $F_{T}$ and an average $x$-ray mean free path $L$ in the pinhole substrate of density $\rho$. The $x$-ray energy density $P_{p}$ entering the inner pinhole walls, which determines the rate of pinhole closure, scales as:

$$
\mathrm{P}_{\mathrm{p}} \sim\left(\mathrm{F}_{\mathrm{T}} / \mathrm{L}\right)\left(\mathrm{r}^{2} / \mathrm{p}^{2}\right)
$$

For a given pinhole radius a, the importance of pinhole closure is determined by the product of the rarefaction sound speed $\mathrm{c}_{\mathrm{s}}$ and $\mathrm{x}$-ray 
illumination duration $\tau$. In addition, since $c_{s}=\sqrt{ }\left(P_{p} / \rho\right)$, substituting for $P_{p}$ in Eq. (14):

$$
\mathrm{c}_{\mathrm{s}} \tau / \mathrm{a} \sim\left[\left(\mathrm{F}_{\mathrm{T}} / \mathrm{a}^{2} \rho \mathrm{L}\right)\left(\mathrm{r}^{2} / \mathrm{p}^{2}\right)\right]^{1 / 2} \tau
$$

If we now stipulate for adequate signal-to-noise that the number of photons $\mathrm{N}$ collected / resolution element must be kept fixed when transitioning from Nova to NIF, then for a given detector gate duration, $\mathrm{N}$ scales as:

$$
\mathrm{N} \sim \mathrm{F}_{\mathrm{T}}\left(\mathrm{a}^{4} / \mathrm{p}^{2}\right) / \tau
$$

We note that for a given pinhole radius a and value of $\mathrm{N}$, Eq. (16) shows that there is a limit on how large $\mathrm{p}$ can become as determined by the peak $x$-ray intensity $\mathrm{F}_{\mathrm{T}} / \tau$ and hence laser intensity achievable. Substituting for Eq. (16) into Eq. (15):

$$
\mathrm{c}_{s} \tau / \mathrm{a} \sim\left(\mathrm{Nr}^{2} / \mathrm{a}^{6} \rho \mathrm{L}\right)^{1 / 2} \tau^{3 / 2}
$$

Eq. (17) shows that the fractional pinhole closure for an optimized experiment does not depend on the pinhole stand-off distance $\mathrm{p}$, since the condition for constant fluence at the pinhole ensures constant $N$ (Eq. (16)) and constant energy density (Eq. (14)) simultaneously. For fixed values of $\mathrm{N}, \mathrm{r}, \mathrm{a}, \rho$ and L, Eq. (17) also warns that the closure would be $15 \mathrm{x}$ worse on NIF if $x$-ray emission durations were $6 x$ longer. However, there are many NIF experiments for which the episodes of peak laser intensity or high plasma energy density which generate most of the harder x-rays of interest for imaging will not be much longer than for current Nova and Omega experiments. Examples include imaging during the peak drive of the NIF ignition pulse ( $3 \mathrm{x}$ longer), imaging the implosion $\mathrm{x}$-ray burst (same duration) and gated point projection imaging using backlit pinholes (same duration). Specifically, since $5 \mu \mathrm{m}$ diameter pinholes at $\mathrm{p}=4 \mathrm{~mm}$ from Nova implosions have survived long enough to take detailed core snapshots ${ }^{2}$, such $5 \mu \mathrm{m}$ pinholes should also be able to capture detailed NIF core snapshots of similar size. 
We consider remedies for those multi-keV imaging experiments where the self-emission or area backlighter size $\mathrm{r}$ is large, where pinhole exposure to x-rays cannot be kept brief, or when the snapshots are taken many ns after a first exposure to $\mathrm{X}$-rays has occurred. First, by tamping the pinholes with low $\mathrm{Z}$ materials, closure should be delayed. Second, one could allow for pinhole closure before the snapshot by deliberately starting with larger pinholes. Third, we use the fact that Eq. (17) shows a strong dependence of relative closure on the value of the initial pinhole radius a. Optimizing the pinhole size to achieve diffraction-limited resolution ${ }^{13}, \mathrm{a}-$ $\sqrt{ }(\mathrm{p} \lambda)$, and assuming the $\mathrm{x}$-ray $\mathrm{mfp}$ in the pinhole substrate is $\sim 1 / \lambda^{3}$, Eq. (15) becomes:

$$
\mathrm{c}_{\mathrm{s}} \tau / \mathrm{a} \sim\left(\mathrm{Nr}^{2} / \mathrm{p}^{3} \rho\right)^{1 / 2} \tau^{3 / 2} \sim(\tau / \mathrm{p})^{3 / 2}
$$

So, by increasing p as fast as $\tau$, Eq. (18) suggests one can control pinhole closure. The degradation in diffraction-limited resolution by increasing $\mathrm{p}$ can be at least partially cancelled by noting that the hotter and larger NIF sources and samples will often require shorter wavelength imaging.

Summarizing, there is no minimum limit on pinhole stand-off distance as set by closure by hard x-rays; one can always keep the fluence fixed at the pinhole by filtering harder as the pinhole is moved in. The percentage closure can be mitigated by limiting the duration of the exposure to $\mathrm{x}$-rays, by tamping the pinholes or by allowing for some closure during the experiment.

For soft x-ray imagers or achromatically-filtered diodes ${ }^{14}$ which use pinhole arrays or slits, closure is also determined by Eq. (15) which can be rewritten as:

$$
\mathrm{c}_{\mathrm{s}} \tau / \mathrm{a} \sim\left(\mathrm{E} / \mathrm{a}^{2} \rho L \mathrm{p}^{2}\right)^{1 / 2} \tau
$$

Setting $\mathrm{a} \sim V_{\mathrm{p}} \lambda$, assuming $\mathrm{L} \sim \mathrm{L}_{0} / \lambda^{3}$ as before, and substituting for the substrate opacity $\kappa=1 / \rho \mathrm{L}_{0}$ : 


$$
\mathrm{c}_{\mathrm{s}} \tau / \mathrm{a} \sim\left(\mathrm{E} \lambda^{2} \kappa / \mathrm{p}^{3}\right)^{1 / 2} \tau
$$

For the same substrate material (e.g. Ta) and photon wavelength, Eq. (20) suggests $\mathrm{p} \sim \mathrm{E}^{1 / 3} \tau^{2 / 3}$ must be $15 \mathrm{x}$ larger at NIF. For spectrometers and imagers, this is only a slightly greater restriction than the condition of maintaining adequate photon statistics $(\mathrm{p}=10 \mathrm{x})$. From Nova experience, slits on streaked soft x-ray imagers (SXI) and pinholes on soft X-ray $2 \mathrm{D}$ imagers (SXRFC) have survived at $5 \mathrm{~cm}$ and at $10 \mathrm{~cm}$ respectively. Scaled to NIF, the maximum soft $x$-ray aperture stand-off distances are $75 \mathrm{~cm}$ and $1.5 \mathrm{~m}$. Again, it would be useful to find the true limits on $\mathrm{p}$ by tests at Omega. Clearly, pinhole and slit tamping is not available for soft $\mathrm{x}$-ray imaging. However, Eq. (20) does suggest a different strategy for mitigating closure for soft x-ray imaging: switching to a lower Z, lower opacity substrate material. The issue of substrate transmission of higher photon energies can be mitigated by placing mirrors and filters downstream and by making the pinhole substrate thicker. This strategy might be especially helpful when viewing softer photons from large, colder hohlraums.

For the pinhole arrays providing achromatic filtering for diodes, closure at NIF scale should not be an issue since current arrays which survive many shots and are already at $1.5 \mathrm{~m}-2 \mathrm{~m}$ at Omega and Nova will be positioned at $5-7 \mathrm{~m}$ on NIF. In all cases, we expect that the pinholes and slits used in soft $\mathrm{x}$-ray instruments may not survive for a second shot (i.e. may melt) and hence would be replaced on evcry shot.

We now consider closure issues for the newly developed technique of pinhole apertured point projection backlighting. This technique uses pinholes of size a placed between the backlighter source of size $s$ and the backlit sample of size $\mathrm{r}$. Let the distance between the pinholes and sample (backlighter) be p' (p"). For the backlighter to fully illuminate the sample in this case, simple geometry in the limit $s>>$ a yields:

$$
\mathrm{p}^{\prime \prime} / \mathrm{p}^{\prime} \leq \mathrm{s} / \mathrm{r}
$$

Since $\mathrm{p}$ " is $<<\mathrm{p}$ ' because $\mathrm{s}$ can be $<<\mathrm{r}$ (typical of point backlighters), we assume the main threat for pinhole closure comes from backlighter $\mathrm{x}$ - 
rays, not target or sample self-emission. In this case, $r$ is replaced by $s$ and $p$ by p" in Eq. (15) while p is replaced by p' + p" in Eq. (16). Eq. (17) can then be rewritten as:

$$
c_{s} \tau / a \sim\left[N^{2}\left(p^{\prime}+p^{\prime \prime}\right)^{2} /\left(p^{\prime \prime 2} a^{6} \rho L\right)\right]^{1 / 2} \tau^{3 / 2}
$$

Substituting for Eq. (21) in Eq. (22) with p" $<<$ p', one recovers Eq. (17) exactly. So again there is no restriction on the value of p' and hence p" if one is willing to filter hard at the pinhole. $25 \mu \mathrm{m}$ diameter backlit pinholes at $\mathrm{p} "=500 \mu \mathrm{m}$ did not $\operatorname{close}^{5}$ at Nova for $\tau=3 \mathrm{~ns}$. Moreover, these early experiments were photon rich ( $\mathrm{N}$ larger than required) and used a value of $\mathrm{p} " \approx 6 \mathrm{x}$ smaller $^{3}$ than required by Eq. (22) for alignment tolerance reasons. Hence, on NIF, for the same accessible backlighter spot size and value of p', one could use a value of p" $=3 \mathrm{~mm}$ and by Eq. (21) suffer no significant closure for an untamped pinhole $(6)^{1 / 3} \mathrm{x}$ smaller, $\approx 14 \mu \mathrm{m}$ in diameter. For even better resolution with adequate photon statistics and field-of-view, tamped pinholes will probably be required.

\section{3) Imaging Optics}

We consider multi-keV imaging optics protected by thick prefilters first. We assume the $\mathrm{x}$-ray damage threshold is proportional to the $\mathrm{x}$-ray energy density absorbed by the crystal, which is independent of incident angle and given by Eq. (14) as $\sim \mathrm{E} / \mathrm{Lp}^{2}$. Hence a $3.5 \mathrm{keV}$ curved crystal imager which survived multiple shots ${ }^{15}$ at $p=8 \mathrm{~cm}$ at Nova should survive at $80 \mathrm{~cm}$ at NIF. Consider the scaling for shorter wavelength operation that will often be required at NIF. Assuming a fixed conversion efficiency of $x-$ rays into the prefilter and Bragg peak bandpasses, and substituting for the average $x$-ray mfp $L \sim 1 / \lambda^{3}$, Eq. (14) can be rewritten as:

$$
\mathrm{P}_{0} \sim \mathrm{E} \lambda^{3} / \mathrm{p}^{2}
$$

Hence, if we cut the imaging wavelength by 3 at NIF, Eq. (23) stipulates that $\mathrm{p}$ need only increase by $\approx 2 \mathrm{x}$ to say $20 \mathrm{~cm}$. This could be vital in compensating for the associated decreased Bragg reflectivity at shorter wavelengths. This is also consistent with placing small thick prefilters at a 
minimum distance of $10 \mathrm{~cm}$ as discussed earlier. Finally, the detectors for such optics can be shielded from a direct line-of-sight of the target, so their minimum distance $\mathrm{q}$ will be set by the requirement of adequate magnification rather than damage constraints.

Survival of expensive multilayers used in soft x-ray imaging is clearly more problematic since incident soft $x$-ray fluences are usually larger than hard $\mathrm{x}$-ray fluences. An extensive experimental and theoretical review of multilayer damage ${ }^{16}$ sets the soft $x$-ray $(200-400 \mathrm{eV})$ damage threshold at $0.1 \mathrm{~J} / \mathrm{cm}^{2}$. We evaluate the minimum stand-off distance based on this number since there is no prior experience using multilayers in indirect-drive configurations at the Nova 10-beam or Omega 60-beam chamber. Consider viewing a $200 \mathrm{eV}, 15 \mathrm{~ns}$ Planckian source through a $2.5 \mathrm{~mm}$ diameter hohlraum diagnostic hole. The total fluence at a distance $\mathrm{p}$ is $\approx 1 / \mathrm{p}^{2} \mathrm{~J} / \mathrm{cm}^{2}$ with $\mathrm{p}$ in $\mathrm{m}$. Hence, the soft $\mathrm{x}$-ray multilayer stand-off distance is of order 3 $\mathrm{m}$, consistent with other soft $\mathrm{x}$-ray filter and detector stand-off distances discussed in Section IIIb1.

\section{4) Crystal Spectrometers}

Since the film in the $2 \mathrm{keV}$ Nova HOPS spectrometer ${ }^{17}$ survived at $\mathrm{q}=$ $10 \mathrm{~cm}$, Eq. (23) suggests a similar NIF HOPS detector would survive at $\mathrm{q}=$ $1 \mathrm{~m}$. The above argument on imaging crystal survivability is also applicable to dispersing crystals, setting $\mathrm{p}=80 \mathrm{~cm}$. In general, the ratio of $\mathrm{p} / \mathrm{q}$ as determined by damage should be $\geq 1$ for spectrometers because the detector by definition is shielded from the direct line-of-sight and only sees Bragg resonant $\mathrm{x}$-rays. Let us now examine how an optimized $\mathrm{p} / \mathrm{q}$ ratio $\approx 1$ affects spectrometer designs scaled to NIF. We assume that a fixed relative $\mathrm{x}$-ray wavelength coverage $\Delta \lambda / \lambda$ must be maintained. For a flat crystal, and assuming an average incident grazing angle $\theta<1$ and a range of incident angles $\Delta \theta<<1$ :

$$
\Delta \lambda / \lambda \approx \mathrm{b} /(\mathrm{q} \tan \theta) \approx \ell / \mathrm{p}
$$

where $\mathrm{b}$ is the detector dimension in the dispersion direction, and $\ell$ is the crystal length. Eq. (24) shows that, independent of the value of q, one 
can increase the odds of crystal survivability by increasing $\ell$ and $p$ together. So using Eq. (24) to scale from existing Nova survey spectrometers with $\mathrm{p} \approx$ $25 \mathrm{~cm}$ to a NIF spectrometer with $\mathrm{p}=80 \mathrm{~cm}, \ell$ must increase by $\approx 3 \mathrm{x}$. The scaling of detector size $b$ depends on both $q$ and $\theta$. One could keep $b$ fixed by reducing $\tan \theta \approx \theta$ by $\mathrm{q}_{\mathrm{Nova}} / \mathrm{q}_{\mathrm{NIF}}=50 / 100=1 / 2$. However, reducing $\theta$ (from a current $6^{\circ}$ to say $3^{\circ}$ ) leads to tighter alignment tolerances in the positioning of crystals and shielding for direct line-of-sight. If $\theta$ is kept fixed, than $\mathrm{b}$ must be increased by $2 \mathrm{x}$ (by switching from $30 \mathrm{~mm}$ to $60 \mathrm{~mm}$ long $\mathrm{MCPs}^{18}$ and streak camera photocathodes ${ }^{19}$ now available and readily accomodated by DIMs). Note that we are only arguing for a $2-4 \mathrm{x}$ larger detector area for the Bragg spectrometer subset of DIM-based diagnostics, so the previous assumption of a constant total diagnostic cross-sectional area as we transition from Nova to NIF is still barely violated.

\section{5) Soft X-ray Spectrometers}

We consider the scaling for soft x-ray spectrometers consisting of reflection gratings and transmission gratings. In these instruments, the gratings are usually preceded by spatially-imaging slits at distance $\mathrm{p}$, of width a and length $\mathrm{h}$. The $\mathrm{x}$-ray fluence $\mathrm{F}_{\mathrm{g}}$ at the grating at distance $\mathrm{q}$ is then given by:

$$
\mathrm{F}_{\mathrm{g}} \sim \mathrm{T}^{4} \tau \mathrm{ha} / \mathrm{q}^{2}
$$

where $\mathrm{T}^{4} \tau$ is $\sim$ to an optically thick radiation fluence at the source. If the slit height $\mathrm{h}$ scales with the source size $\mathrm{r}$, and we assume a diffraction-limited slit width $\mathrm{a} \sim \sqrt{\mathrm{p}} \lambda \sim \sqrt{\mathrm{p}} \mathrm{T} \mathrm{T}$, then for a hohlraum with $\mathrm{E} \sim \mathrm{T}^{3.5} \tau \mathrm{r}^{2}$ :

$$
\mathrm{F}_{\mathrm{g}} \sim(\mathrm{E} \vee \mathrm{p}) /\left(\mathrm{rq}^{2}\right)
$$

For the same fluence at the slit, $\mathrm{p}$ must be $10 \mathrm{x}$ greater. If $\mathrm{r}$ is $\approx \sqrt{ } 10$ greater, then by Eq. (26), $\mathrm{q} \sim \sqrt{\mathrm{E}}$ is also $10 \mathrm{x}$ larger. So this leads to a straightforward scaling from a current soft $x$-ray streaked grating spectrometer (SXI) with $\mathrm{p}=5-20 \mathrm{~cm}$ and $\mathrm{q}=35 \mathrm{~cm}$ to a NIF SXI with $\mathrm{p}=$ $50 \mathrm{~cm}-2 \mathrm{~m}$ and $\mathrm{q} \approx 3.5 \mathrm{~m}$. Finally, the spectral resolution $\Delta \lambda$ for a given grating period $\mathrm{d}$ is usually set by a combination of the source size, detector 
spatial resolution $\Delta \mathrm{x}$, source-to-grating distance $\mathrm{q}$ and grating-to-detector distance q' as follows:

$$
\Delta \lambda=\mathrm{d}[\Delta \mathrm{x} / \mathrm{q}, \mathrm{r} / \mathrm{q}]_{\max }
$$

For a fixed grating period and detector resolution, Eq. (27) suggests even better spectral resolution is possible at NIF by increasing q' and by the fact that we have stipulated earlier that the ratio $\mathrm{r} / \mathrm{q}$ decreases by $\sqrt{10 \mathrm{x}}$. Optimizing the NIF SXI design as was done for the Nova SXI by equating the two terms in brackets in Eq. (27), q' should increase by $\sqrt{ } 10$, from a current $15 \mathrm{~cm}$ to $\approx 50 \mathrm{~cm}$, leading to a $\sqrt{10}$ improvement in spectral resolution.

The table below summarizes the minimum stand-off distances and detector sizes used at Nova/Omega and proposed for NIF based on achieving adequate photon statistics and robustness to x-ray damage as discussed in Section IIIb. There may be extra limitations on NIF diagnostic stand-off distances based on the number of pieces of shrapnel and shrapnel energy distribution as discussed in Section IIIa2. 


\begin{tabular}{|c|c|c|c|c|c|c|c|}
\hline \multirow[t]{2}{*}{ Diagnostic } & \multirow[t]{2}{*}{ Subsystem } & \multicolumn{3}{|c|}{ Nova/Omega } & \multicolumn{3}{|l|}{ NIF } \\
\hline & & $\begin{array}{l}\mathrm{p}, \mathrm{q} \\
\mathrm{cm}\end{array}$ & $\begin{array}{l}\mathrm{b} \\
\mathrm{cm}\end{array}$ & $\mathrm{M}$ & $\begin{array}{l}\mathrm{p}, \mathrm{q} \\
\mathrm{cm}\end{array}$ & $\begin{array}{l}\mathrm{b} \\
\mathrm{cm}\end{array}$ & $\mathrm{M}$ \\
\hline \multirow{2}{*}{$\begin{array}{l}\text { Hard X-ray } \\
\text { PH Imager }\end{array}$} & Pinhole & 3 & & & 15 & & \\
\hline & Filter+Detector & 38 & 3.5 & $12 \mathrm{x}$ & 90 & 3.5 & $6 \mathrm{x}$ \\
\hline \multirow{2}{*}{$\begin{array}{l}\text { Soft X-ray } \\
\text { PH Imager }\end{array}$} & Pinhole & $>5$ & & & $>75$ & & \\
\hline & Filter+Detector & 50 & 3.5 & $<9 \mathrm{x}$ & 500 & 3.5 & $4 \mathrm{x}$ \\
\hline \multirow{3}{*}{$\begin{array}{l}\text { Target-PH } \\
\text { Imager } \\
\text { (Small FoV) }\end{array}$} & Pinhole & 0.4 & & & 1 & & \\
\hline & Filter+Detector & 16 & 3.5 & $40 \mathrm{x}$ & 100 & 3.5 & $100 \mathrm{x}$ \\
\hline & & & & & & & \\
\hline \multirow{3}{*}{$\begin{array}{l}\text { Target-PH } \\
\text { Backlighter } \\
\text { (Large FoV) }\end{array}$} & Backlighter & 0.05 & & & 0.3 & & \\
\hline & Pinhole & 2 & & & 5 & & \\
\hline & Filter+Detector & 10 & 3.5 & $6 \mathrm{x}$ & 30 & 3.5 & $7 \mathrm{x}$ \\
\hline \multirow{3}{*}{$\begin{array}{l}\text { Hard X-ray } \\
\text { Crystal } \\
\text { Imager }\end{array}$} & Filter+Crystal & 8 & & & 80 & & \\
\hline & \begin{tabular}{|l} 
Filter+Detector \\
\end{tabular} & 50 & 3.5 & $7 \mathrm{x}$ & 500 & 3.5 & $7 \mathrm{x}$ \\
\hline & & & & & & & \\
\hline \multirow{3}{*}{$\begin{array}{l}\text { Soft X-ray } \\
\text { Multilayer } \\
\text { Imager }\end{array}$} & Filter+ML & & & & 300 & & \\
\hline & Filter+Detector & & & & 600 & 3.5 & $3 \mathrm{x}$ \\
\hline & & & & & & & \\
\hline \multirow{3}{*}{$\begin{array}{l}\text { Hard X-ray } \\
\text { Spectrometer }\end{array}$} & \begin{tabular}{|l} 
Filter/Slit \\
\end{tabular} & $>5$ & & & $>15$ & & \\
\hline & Crystal & 8 & & & 80 & & \\
\hline & Filter+Detector & 50 & 3 & $<9 \mathrm{x}$ & 100 & 6 & $<6 \mathrm{x}$ \\
\hline \multirow{3}{*}{$\begin{array}{l}\text { Soft X-ray } \\
\text { Spectrometer }\end{array}$} & Slit & $>5$ & & & $>50$ & & \\
\hline & \begin{tabular}{|l|} 
Filter+Grating \\
\end{tabular} & 35 & & & 350 & & \\
\hline & \begin{tabular}{|l} 
Detector \\
\end{tabular} & 50 & 3 & $<9 \mathrm{x}$ & 400 & 3 & $<7 x$ \\
\hline \multirow{3}{*}{$\begin{array}{l}\text { Soft X-ray } \\
\text { Diodes }\end{array}$} & Pinhole Array & 150 & & & 500 & & \\
\hline & Filter+Detector & 200 & & & 700 & & \\
\hline & & & & & & & \\
\hline
\end{tabular}


I thank B. Turner, M. Tobin, D. Eder, B. Hammel and B. MacGowan for critical reviewsand input.

\section{References}

1) A. Burnham amd M. Tobin, private communication

2) J. Koch, "Recent Progress in High-Energy, High-Resolution X-Ray Imaging Techniques for Application to the NIF", Rev. Sci. Instrum. 70 (1999) 525.

3) D.K. Bradley, 4/99 presentation at WBS 2 review.

4) D. Lee and P. Bell, private communication

5) O.L. Landen, "Backlighting for NIF-scale" 5/99 preentation at NIF/HEDS teleconference with LANL.

6) J. Trebes, private communication

7) G. Glendinning, private communication

8) W. Seka (Omega Facility), private communication

9) B. Hockaday, Santa Fe 1993 NIF Diagnostic Workshop, private communication.

10) D.H. Kalantar, "NIF Experiment Configurations" $12 / 98$ presentation at LANL.

11) J.D. Lindl, Phys. Plasmas 2 (1995) 3933.

12) R.E. Turner et. al., "Debris Experiments", Memo TAT 96-051.2, 7/96.

13) J.A. Koch et. al., "High-Energy X-Ray Microscopy Techniques for Laser-Fusion Plasma Research at the National Ignition Facility" Appl. Opt. 37 (1998) 1784.

14) R.E. Turner. et.al.., "Achromatically Filtered Diamond Photoconductive Detectors for High Power Soft X-Ray Flux Measurements", Rev. Sci. Instrum. 70 (1999) 656.

15) C. Back, private communication

16) B.J. MacGowan et. al., "Investigation of Damage to Multilayer Optics in X-Ray Laser Cavities", J. of X-Ray Sci. and Tech. 3 (1993) 231.

17) T. Perry, private communication

18) J. Oertel, private communication

19) P. Jaanimagi, PJX camera (private communication) 